\title{
Clinical Study of Surgical Site Infection
}

\author{
Dr. Balaji Prabhakaran, Dr. Mohamed Afjal, Dr. Saptarshi Paul
}

\begin{abstract}
Background and objective: Study most common organisms encountered and their sensitivity and resistance to antibiotics in postoperative wound infection. Methods: 70 cases of postoperative wound infection were analyzed. Appropriate history and examination was done. Culture and sensitivity reports were reviewed. Results: Most common organism encountered is Pseudomonas (34.3\%) most sensitive antibiotic is amikacin (80\%) and most resistant antibiotics are Colistin (72.9\%). Interpretation and Conclusion: Most common organism in post operative wound infection is Pseudomonas. Most sensitive antibiotic is Amikacin and most resistant is Colistin.
\end{abstract}

Keywords: Surgical Wound Infection; Anti-bacterial Agents; Amikacin; Drug resistance, microbial

\section{Introduction}

Surgical wound infections continue to consume a considerable portion of health care finance. Even though the complete elimination of wound infections is not possible, a reduction of the observed wound infection rate to a minimum level could have marked benefits in terms of both patient comfort and resources used. The modern surgeon cannot escape the responsibility of dealing with infections and in dealing with them, of having the knowledge for the appropriate use of aseptic and antiseptic technique, proper use of prophylactic and therapeutic antibiotics, and adequate monitoring and support with novel surgical and pharmacologic as well as non pharmacologic aids.

\section{Methodology}

The clinical study of surgical infection was conducted at Yenepoya Medical College \& Hospital during the period of October 2013 to October 2015.

Inclusion criteria: Only those cases which will be operated in Yenepoya Medical College \& Hospital will be taken into consideration.

Age limits: 15- 80years

Exclusion criteria: Wound site previously infected will be excluded

\section{Materials and Methods}

An elaborate study of these cases with regard to date of admission, history, clinical features of wound infection, special investigation, type of surgery, preoperative preparation and postoperative management is done till patient is discharged from hospital.

In history, presenting complaints, duration, associated diseases, personal history including diet, smoking, and alcoholism were noted.

Preoperative findings which include preoperative bath, skin preparation, type and time of preparation $(<24$ or $>24$ hours) preparation of bowel, preoperative antibiotics, steroid medication were noted. Operative findings which include, wound irrigative drain and its type (open or closed) noted.
Postoperative findings which include, day of diagnosis of infection, day of $1^{\text {st }}$ dressing and frequency of change of dressing, local application of antibiotics and postoperative antibiotics.

Findings on the day of diagnosis of wound infection were noted which included fever, erythema, discharge, type of discharge.

Wound infection was diagnosed on the basis of definitions given in Oxford textbook of Surgery $2^{\text {nd }}$ edition, swab for culture and sensitivity is collected and sent to laboratory with appropriate specimen (discharge).

The reports for all 70 cases are made into a chart. Each organism cultured is noted and the number of times it is isolated in written correspondingly. This gives the commonest microorganisms in our hospital setting.

\section{Most Sensitive and Resistant Antibiotics}

After the culture of micro-organism, sensitivity test is done. Sensitivity test is done in our laboratory by using;

1) Blood agar plate

2) Mueller's hinston plate

These plates are incubated over night and then the sensitivity is confirmed.

These reports were charted and separate graph was prepared showing the sensitivity and resistance of individual antibiotic. One more graph was prepared by giving one point for each time antibiotic is sensitive and one point for each time antibiotic is resistant. This graph shows the most effective antibiotic which is having highest positive value. 


\section{International Journal of Science and Research (IJSR) \\ ISSN (Online): 2319-7064}

Index Copernicus Value (2013): 6.14 | Impact Factor (2015): 6.391

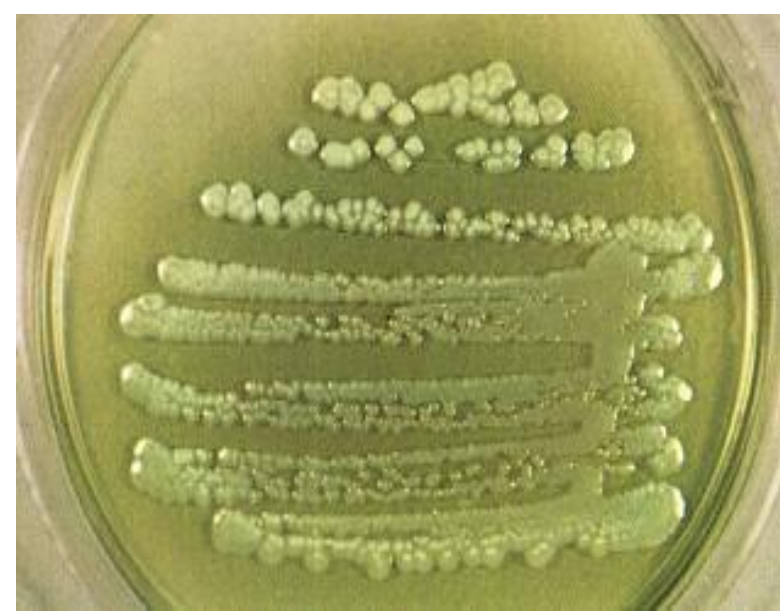

Culture Plate

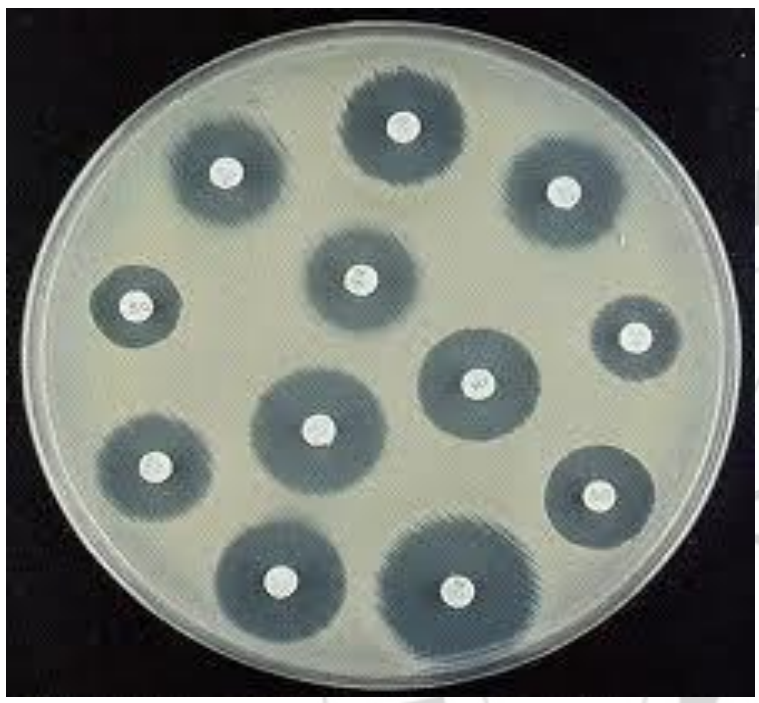

Antibiotic Sensitivity Test

\section{Observation and Results}

Age wise distribution of study subjects:

In this study majority of patients belonged to the age group between 41- 50years. Youngest patient was 15 years old and oldest was 80years. The mean age of the patient affected was 44 years.

\begin{tabular}{|c|c|c|}
\hline & Age & Percent \\
\hline$<\mathbf{2 0}$ & 7 & $10 \%$ \\
\hline $\mathbf{2 1 - 3 0}$ & 11 & $15.7 \%$ \\
\hline $\mathbf{3 1 - 4 0}$ & 13 & $18.6 \%$ \\
\hline $\mathbf{4 1 - 5 0}$ & 16 & $22.9 \%$ \\
\hline $\mathbf{5 1 - 6 0}$ & 9 & $12.9 \%$ \\
\hline $\mathbf{6 1 - 7 0}$ & 7 & $10 \%$ \\
\hline $\mathbf{7 1 - 8 0}$ & 7 & $10 \%$ \\
\hline Total & 70 & $100 \%$ \\
\hline
\end{tabular}

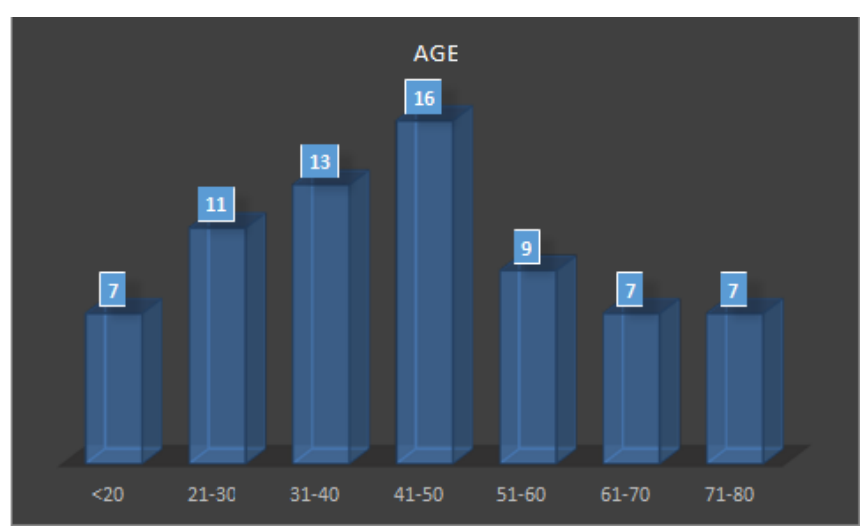

\section{Signs and Symptoms:}

The most common presentation in present series is discharge. Total 51 cases presented with discharge through the wound.

\begin{tabular}{|c|c|c|c|}
\hline & & Count & Column N \% \\
\hline Fever & - & 33 & $47.10 \%$ \\
\hline & + & 37 & $52.90 \%$ \\
\hline Erythema & - & 47 & $67.10 \%$ \\
\hline & + & 23 & $32.90 \%$ \\
\hline Discharge & - & 19 & $27.10 \%$ \\
\hline & + & 51 & $72.90 \%$ \\
\hline
\end{tabular}

\section{Type of Discharge}

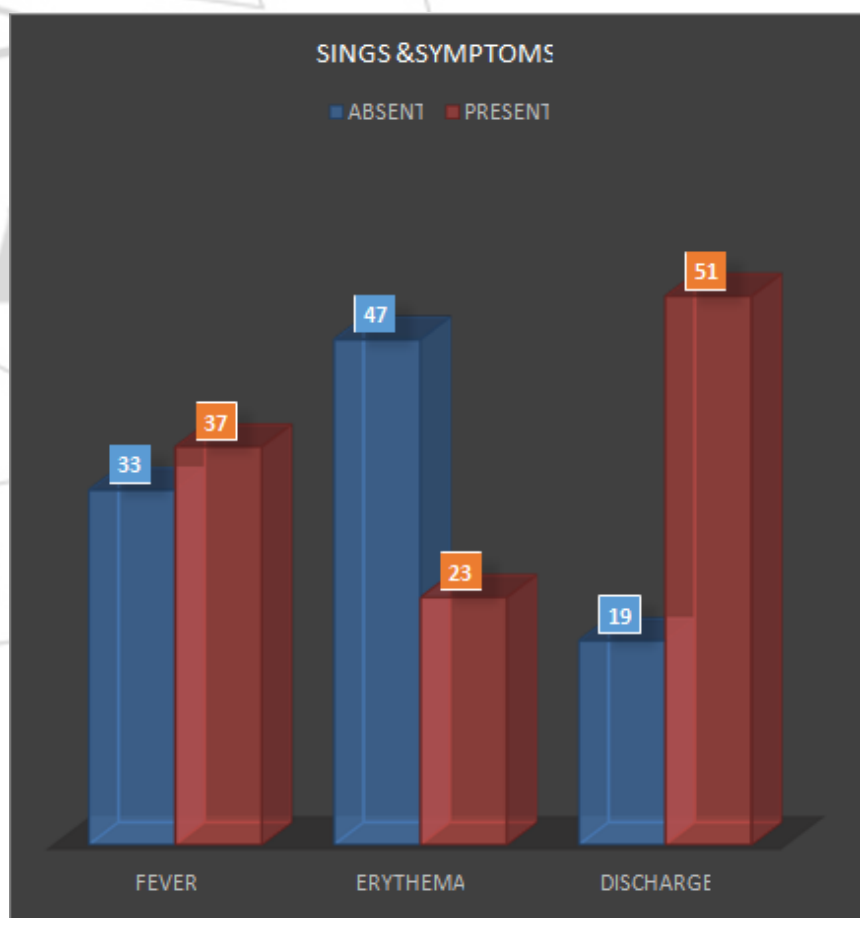

The most common type of discharge was purulent type with percentage of $31.40 \%$ In 22 case the least common type of discharge was Serosanguinous. Only patient presented with Serosanguinous discharge with percentage of $20 \%$ In 14 case. 


\section{International Journal of Science and Research (IJSR) \\ ISSN (Online): 2319-7064}

Index Copernicus Value (2013): 6.14 | Impact Factor (2015): 6.391

\begin{tabular}{|c|c|c|c|}
\hline Discharge Type & Nil & $\mathbf{1 8}$ & $\mathbf{2 5 . 7 0 \%}$ \\
\hline & Purulent & 22 & $31.40 \%$ \\
\hline & Seropurulent & 16 & $22.90 \%$ \\
\hline & Serosanguinous & 14 & $20.00 \%$ \\
\hline
\end{tabular}

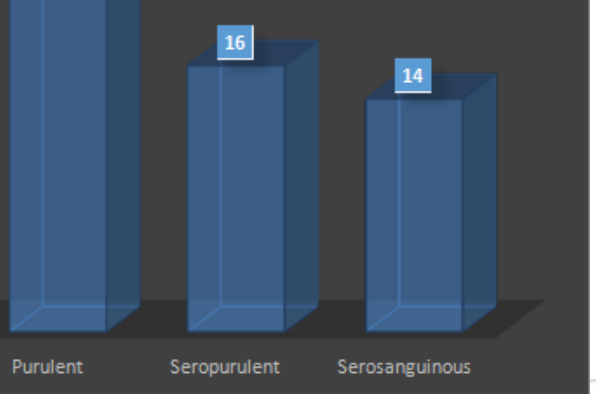

Antibiotics given:

Out of 70 cases 65 cases $(92.90 \%)$ had received preoperative antibiotics. Whereas, 5 cases $(7.10 \%)$ not received preoperative antibiotics and all case received postoperative antibiotics.

\section{Antibiotic}

\begin{tabular}{|c|c|c|c|}
\hline & & Case & $\begin{array}{c}\text { Column N } \\
\%\end{array}$ \\
\hline PRE OP ANTIBIOTIC & NO & 5 & $7.10 \%$ \\
\hline & YES & 65 & $92.90 \%$ \\
\hline POST OP ANTIBIOTIC & YES & 70 & $100.00 \%$ \\
\hline
\end{tabular}

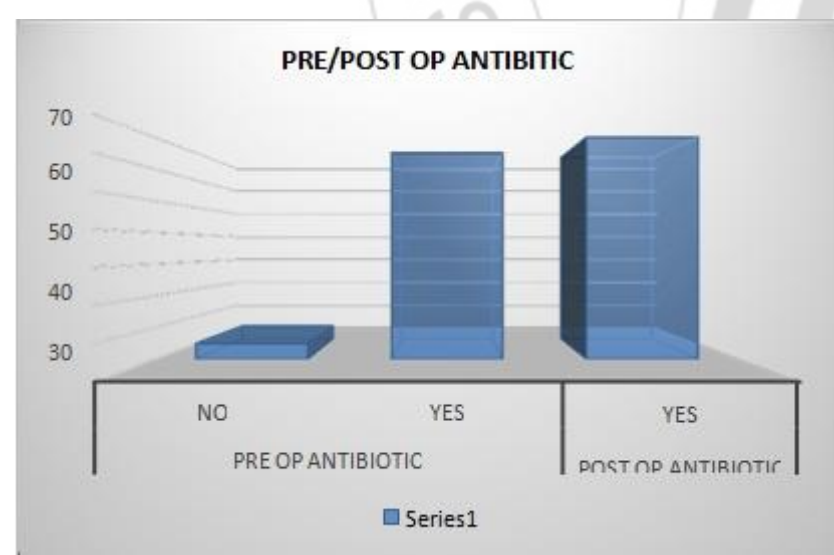

\section{Microorganism:}

Most common microorganism encountered in present series is pseudomonas 24 cases $(34.30 \%)$. Least common micro organism is Staphylococcus i.e 2 case (2.90\%).

Table 10: Showing Microorganisms

\begin{tabular}{|l|c|c|c|}
\hline Microorganism & Acinetobacter & $\mathbf{3}$ & $\mathbf{4 . 3 0 \%}$ \\
\hline & E.Coli & 12 & $17.10 \%$ \\
\hline & Kleibsiella & 12 & $17.10 \%$ \\
\hline & Proteus & 12 & $17.10 \%$ \\
\hline & Pseudomonas & 24 & $34.30 \%$ \\
\hline & Staphylococcus & 2 & $2.90 \%$ \\
\hline & Streptococci & 5 & $7.10 \%$ \\
\hline
\end{tabular}

\section{MICROORGANISM}

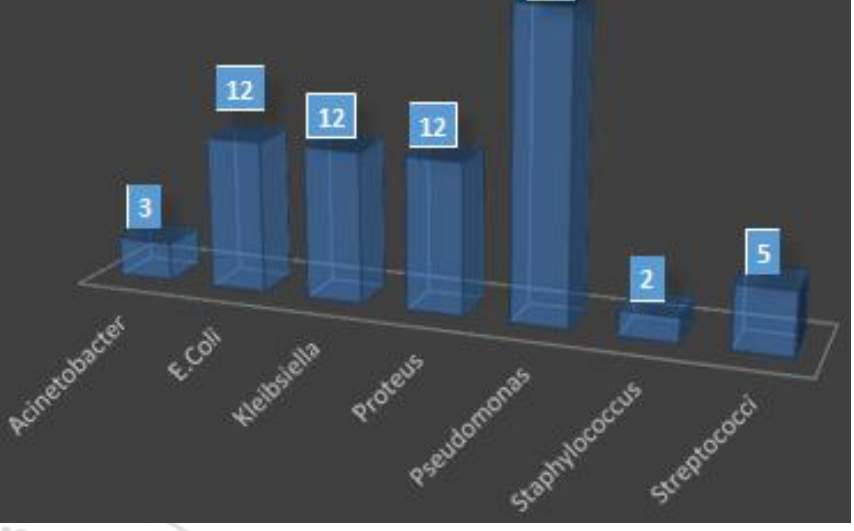

Antibiotics:

Most sensitive antibiotic in present series is Amikacin. Other common sensitive antibiotics are amoxycillin, chloramphenicol, , cefotaxime, azithromycin.

Most resistant antibiotics are Colistin, other resistant imipeneam, ceftriaxone, amoxyclav

Table 11: Showing Antibiotic Sensitive and Resistant

\begin{tabular}{|c|c|c|c|}
\hline$z^{\prime}$ & Sensitive / Resistant & Count & Column N \% \\
\hline Ampicillin & $\mathrm{R}$ & 31 & $44.30 \%$ \\
\hline & $\mathrm{S}$ & 39 & $55.70 \%$ \\
\hline Amoxycillin & $\mathrm{R}$ & 22 & $31.40 \%$ \\
\hline & $\mathrm{S}$ & 48 & $68.60 \%$ \\
\hline Amikacin & $\mathrm{R}$ & 14 & $20.00 \%$ \\
\hline & $(-1)$ & 56 & $80.00 \%$ \\
\hline \begin{tabular}{|l|} 
Chloramphenicol \\
\end{tabular} & $\mathrm{R}$ & 21 & $30.00 \%$ \\
\hline- & $\mathrm{S}$ & 49 & $70.00 \%$ \\
\hline Cefotaxime & $\mathrm{R}$ & 28 & $40.00 \%$ \\
\hline A & 7 & 42 & $60.00 \%$ \\
\hline Ciprofloxacin & $\mathrm{R}$ & 34 & $48.60 \%$ \\
\hline $\mathcal{O}$ & $\mathrm{S}$ & 36 & $51.40 \%$ \\
\hline Ceftriaxone & $\mathrm{R}$ & 43 & $61.40 \%$ \\
\hline$=$ & $\mathrm{S}$ & 27 & $38.60 \%$ \\
\hline Doxycycline & $\mathrm{R}$ & 33 & $47.10 \%$ \\
\hline & $\mathrm{S}$ & 37 & $52.90 \%$ \\
\hline Erythromycin & $\mathrm{R}$ & 38 & $54.30 \%$ \\
\hline & $\mathrm{S}$ & 32 & $45.70 \%$ \\
\hline Gentamycin & $\mathrm{R}$ & 33 & $47.10 \%$ \\
\hline & $\mathrm{S}$ & 37 & $52.90 \%$ \\
\hline Piperacillin & $\mathrm{R}$ & 35 & $50.00 \%$ \\
\hline & $\mathrm{S}$ & 35 & $50.00 \%$ \\
\hline AZITHROMYCIN & $\mathrm{R}$ & 31 & $44.30 \%$ \\
\hline & $\mathrm{S}$ & 39 & $55.70 \%$ \\
\hline AMOXYCLAV & $\mathrm{R}$ & 42 & $60.00 \%$ \\
\hline & $\mathrm{S}$ & 28 & $40.00 \%$ \\
\hline IMIPENEM & $\mathrm{R}$ & 42 & $60.00 \%$ \\
\hline & $\mathrm{S}$ & 28 & $40.00 \%$ \\
\hline SULBACTUM & $\mathrm{R}$ & 40 & $57.10 \%$ \\
\hline & $\mathrm{S}$ & 30 & $42.90 \%$ \\
\hline \multirow[t]{2}{*}{ Colistin } & $\mathrm{R}$ & 51 & $72.90 \%$ \\
\hline & $\mathrm{S}$ & 19 & $27.10 \%$ \\
\hline
\end{tabular}




\section{International Journal of Science and Research (IJSR) \\ ISSN (Online): 2319-7064}

Index Copernicus Value (2013): 6.14 | Impact Factor (2015): 6.391

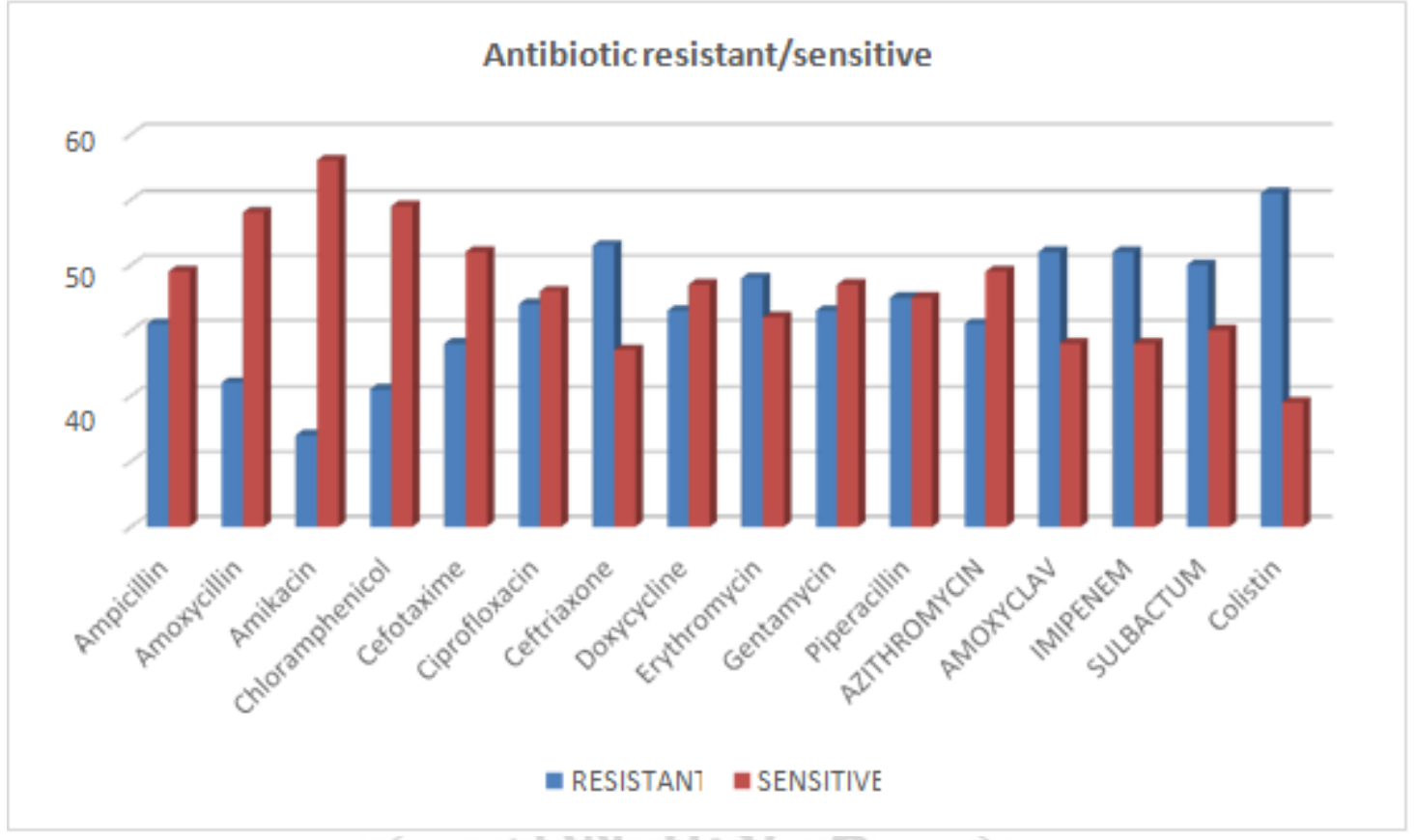

\section{Discussion}

The present study was conducted in YENEPOYA MEDICAL COLLEGE AND HOSPITAL. This is cross sectional type of study.

\section{Microorganism:}

Most common organism encountered in postoperative wound infection in this study is PSEUDOMONAS, in 24 cases accounting for $34.30 \%$. The second common organism in this study is E.Coli, in 12 cases accounting for $17.10 \%$. The least common organism was STAPHYLOCOCCUS and ACINETOBACTER.

\begin{tabular}{|c|c|c|c|}
\hline AUTHOR & BHIRUD et al & TRIPATHY et al & MY STUDY \\
\hline $\begin{array}{c}\text { Commonest } \\
\text { Organism }\end{array}$ & E coli & PSEUDOMONAS & PSEUDOMONAS \\
\hline
\end{tabular}

Tripathy et al, shows PSEUDOMONAS as commonest organism inpostoperative wound infection. Our values match with the observations by tripathy et al.

Bhirud et al, shows that Ecoli as predominant microorganism isolated i.e. $40 \%$ and $2^{\text {nd }}$ most common organism

\section{Antibiotics Sensitivity and Resistance}

\begin{tabular}{|c|c|c|c|}
\hline Author & Kowl et al101 & Tripathy & My study \\
\hline $\begin{array}{l}\text { Antibiotic } \\
\text { Sensitive }\end{array}$ & \begin{tabular}{|c|} 
Cloxacillin \\
Cotrimoxazole \\
Chloramphenico \\
Cephaloridine \\
Gentamicin \\
Kanamycin
\end{tabular} & $\begin{array}{c}\text { Co-trimoxazole } \\
\text { Chloramphenico } \\
\text { Gentamicin }\end{array}$ & $\begin{array}{c}\text { Amikacin } \\
\text { Amoxycillin, } \\
\text { ChloramphenicoL, } \\
\text { Cefotaxime, } \\
\text { azithromycin. }\end{array}$ \\
\hline $\begin{array}{c}\text { Antibiotic } \\
\text { resistant }\end{array}$ & $\begin{array}{l}\text { Piperacillin } \\
\text { Ceftriaxone } \\
\text { Ampicillin }\end{array}$ & $\begin{array}{c}\text { Penicillin } \\
\text { Tetracycline } \\
\text { Ampicillin } \\
\text { Erythromycin }\end{array}$ & $\begin{array}{l}\text { Colistin } \\
\text { imipenem, } \\
\text { ceftriaxone, } \\
\text { amoxyclav }\end{array}$ \\
\hline
\end{tabular}

In our study the common sensitive antibiotics are Amikacin, Amoxycillin, ChloramphenicoL, Cefotaxime, azithromycin.

The common resistant antibiotics are Colistin imipenem, Ceftriaxone, amoxyclav. The reason for sensitivity of the antibiotics in our series is probably due to their broad spectrum and less routine use due to unavailability of oral preparation, cost. Therefore less commonly prescribed as outpatient. The reason for resistance of antibiotics in our series is probably due to their more common use in outpatient department and indoor patients for prolonged period.

Kowli et al, shows gentamycin, Cloxacillin, cotrimoxazole, Chloramphenicol more sensitive antibiotic postoperatively for gram positive aerobes and cephaloridine, Gentamycin, Kanamycin sensitive against gram negative aerobes.

Tripathy et al, observed that organisms were less sensitive to penicillin, tetracycline, ampicillin and erythromycin in that order of descending magnitude as compared to cotrimoxazole, gentamycin and chloramphenicol.

\section{Type of Surgery}

\begin{tabular}{|c|c|c|c|}
\hline Type of operation & Bhirud et al & My study & Percentage \\
\hline Clean & 4 & 15 & $21.4 \%$ \\
\hline Clean contaminated & 7 & 23 & $32.9 \%$ \\
\hline Contaminated & 16 & 10 & $14.3 \%$ \\
\hline Dirty & 47 & 22 & $31.4 \%$ \\
\hline
\end{tabular}

In present study, the wound infection rate for clean, clean contaminated, contaminated and dirty cases is $21.4 \%$, $32.9 \%, 14.3 \%$ and $31.4 \%$ respectively. The reason for this increasing rate of wound infection is probably, increasing contamination during surgery. 


\section{International Journal of Science and Research (IJSR)}

ISSN (Online): 2319-7064

Index Copernicus Value (2013): 6.14 | Impact Factor (2015): 6.391

\section{To Reduce SSI:}

The principle of disinfection should be followed meticulous.

While operating ACUTE APPENDICITIS extra care should be taken ensure that the operating field should not be contaminated with pus. In obstructed hernia toxic fluid should let out first from fundus of sac.

\section{Conclusion}

- Majority of patients belonged to age group of 41-50 years which account for $22.9 \%$.

- Out of 70 cases, 14 cases were having ACUTE APPENDICITIS accounting for $20 \%$.

- Most of the patients presented with discharge through the wound. The most common type of discharge was purulent. Total 53 cases $(72.9 \%)$ presented with discharge.

- 23 cases out of 70 have undergone surgery which is classified as clean contaminated accounting for $32.90 \%$.

- Out of 70 cases $65(92.90 \%)$ cases received preoperative antibiotics, $5 \%$ not received preoperative and all cases resived postoperative antibiotics.

- In $34.30 \%$ (24) cases Pseudomonas was the microorganism found on culture.

- More sensitive antibiotics are Amikacin, Amoxycillin, ChloramphenicoL, Cefotaxime.

- More resistant antibiotics are Colistin, IMIPENEM, Ceftriaxone, amoxyclav

\section{References}

[1] Anthony T, Murray BW, Sum-Ping JT etal. Evaluating an evidence-based bundle for preventing surgical site infection: a randomized trial. ArchSurg. 2011; 146(3):263-269

[2] AwadSS. Adherence to surgical care improvement project measures and post-operative surgical site infections. Surg Infect (Larchmt). 2012; 13(4):234-237

[3] Awad SS, Palacio CH, Subramanian A, etal. Implementation of a methicillin-resistant Staphylococcusaureus (MRSA) prevention bundle results in decreased MRSA surgical site infections. AmJSuG. 2009; 198(5):607-610

[4] Aragon D, SoleML. Implementing best practice strategies to prevent infection in the ICU. CritCareNursClinNorthAm. 2006; 18(4):441-452

[5] Bessesen MT, Lopez K, Guerin K, etal. Comparison of control strategies for methicilli n-resistant Staphlococcusaureus. AmJ Infect Control. 2013; 41(11):1048-1052

[6] BullA, WilsonJ, WorthLJ, etal. A bundle of care to reduce colorectal surgical infections: an Australian experience. JHospInfect. 2011; 78(4):297-301

[7] CaseyAL, ElliotTS. Progress in the prevention of surgical site infection. CurrOpin Infect Dis. 2009; 22(4):370-375
[8] CimaR, DankbarE, LovelyJ, etal. Colorectal surgery surgical site infection reduction program: anational surgical quality improvement program-Driven multidisciplinary ysingle- institution experience. Jam Coll Surg, 2013; 216(1):23-33.

[9] CrawfordT, RodvoldKA, SolomkinJS. Vancomycin for surgical prophylaxis. Clin Infect Dis. 2012; 54(10):1474-1479.

[10]CrollaRM, vanderLaanL, VeenEJ, HendriksY, vanSchendelC, Kluytmans J. Reduction of surgical site infections after implementation of a bundle of care. PloSOne. 2012; 7(9):e44599

[11]Dyrkorn OA, Kristoffersen M, Walberg M. Reducing post-caesarean surgical wound infection rate: an improvement projectina Norwegian maternity clinic. BMJQualS af. 2012; 21(1):206-210

[12] EdmistonCE, DaoudFC. Is there an evidence-based argument for embracing anti Microbial (triclosan)-coated suture technology to reduce the risk for surgical-site infections?:Ameta-analysis. Surgery

[13] GrafK, SohrD, HaverichA, KühnC, Gastmeier P, ChabernyIF. Decrease of deepsternal surgical site infection rates after cardiac surgery by a comprehensive infection control program. Interact Cardiovasc Thorac Surg. 2009; 9(2):282-286.

[14] Humphreys H. Preventing surgical site infection. Where now? J Hosp Infect. 2009; 73(4):316-322.

[15] Jain M, Miller L, Belt D, King D, Berwick D M. Declinein ICU adverse events, nosocomial infections and cost through a quality improvement initiative focusing on team Work and culture change. Qual Saf Health Care. 2006; 15(4):235-239 